\title{
Cultivating Organizations as Healing Spaces: A Typology for Responding to Suffering and Advancing Social Justice
}

\author{
Reut Livne-Tarandach ${ }^{1}$ (D) Erica Steckler ${ }^{2}$ (D) . Jennifer Leigh ${ }^{3}$ (D) \\ Sara Wheeler-Smith ${ }^{1}$ (iD
}

Received: 22 June 2021 / Accepted: 11 November 2021 / Published online: 10 December 2021 (c) The Author(s), under exclusive licence to Springer Nature Switzerland AG 2021

\begin{abstract}
Historic inequities exacerbated by COVID-19 and spotlighted by social justice movements like Black Lives Matter have reinforced the necessity and urgency for societies and organizations to bring healing into focus. However, few integrated models exist within management and organization scholarship to guide practice. In response, our focus aims to unpack how organizations can become healing spaces. This paper offers a holistic definition of healing as the foundation for a new conceptual model of organizations as healing spaces. Drawing upon literature from clinical psychology, social psychology, and political science, we identify four perspectives that address healing in organizational contexts: (1) restorative justice, (2) posttraumatic growth, (3) relational cultural theory, and (4) dignity. These healing modalities represent prominent views of how healing can be achieved at the individual, dyadic, organizational, and societal levels. Synthesizing and building on these perspectives, we develop a typology that illustrates three ways organizations can function as healing spaces - Emergent, Endeavoring, and Exemplifying — representing a range of opportunities for how organizations can better respond to suffering. These spaces of healing are differentiated across seven dimensions, including source of harm, recipients of healing, facilitators of healing, focus of healing, length and strength of organizational attention, process of healing, and activators or enablers of healing. This research contributes to organizational healing research and to nascent social justice discussions in the management literature by exploring a range of opportunities for how organizations can better respond to suffering and substantively contribute to remedying harm from systematic bias against marginalized groups via healing.
\end{abstract}

Keywords Organizational healing $\cdot$ Social justice $\cdot$ Harm $\cdot$ Suffering $\cdot$ Dignity $\cdot$ Healing

Healing is both an exercise and an understanding...

...To know healing is to know that all life is one.

- Excerpts from Margaret Torrie's The Intention

Reut Livne-Tarandach

rlivnetarandach01@manhattan.edu

Extended author information available on the last page of the article 
Taking stock of the first quarter of the twenty-first century, the imperative for recognizing and healing social injustice across every segment and through each layer of our global society is increasingly clear. A 2006 report by the Department of Economic and Social Affairs of the United Nations frames social injustice as global and persistent, requiring collective responsibility along with comprehensive strategies and collaboration to redress. In support of the "universal aspiration for social justice" (p. 6), in 2008 the International Labour Organization (ILO) adopted its Declaration on Social Justice for a Fair Globalization for the purpose of accelerating the positive transformation of mutually beneficial economic and social development (ILO 2008). Despite the recognition of social justice as a necessary bedrock for realizing our best intentions and earnest commitments for a peaceful, flourishing, and sustainable society, enduring inequality and social strife continue to characterize the modern era.

In parallel, the for-profit enterprises in which we work continue to gain recognition and traction as increasingly influential actors and change agents in society (Drucker 1999). Recent analysis by researchers at the McKinsey Global Institute on twenty-first century companies highlights the critical questions today's firms face about "their responsibility for social well-being on a global as well as local scale" (Manyika and Tuin 2020). Such questions grow from accountability demands by stakeholders regarding organizations' responsibilities for social issues and their expectations of organizations for substantively addressing and remedying these (Porter and Kramer 2006). At the same time, a broadening public awareness of social injustice and resultant suffering - including systemic discrimination and institutionalized racism - highlights insufficiencies and gaps in dominant responses by organizations to societal inequality and inequity.

Importantly, the role organizations could - and we argue should - embrace for nurturing and stewarding social justice and healing beyond their own architectures and boundaries has remained largely unspecified. For example, while organizational justice focuses primarily on fairness of interactions and outcomes for individual actors (Colquitt et al. 2005) and workplace diversity, equity, and inclusion (DEI) efforts focus on social group composition and implications (Thomas and Ely 1996; Ely and Thomas 2020) in organizations, neither advances practices for how organizations can better or more proactively engage with social justice across levels and work toward healing individuals and collectives who have experienced injustice. Further, while the concept of corporate social justice (CSJ) reframes corporate social responsibility (CSR) to include stewardship of the interests of harmed or disadvantaged societal groups (Zheng 2020), it does not address healing directly. Overall, extant literature in the organizational field largely fails to account for systemic and holistic approaches in fostering effective organizational healing responses to social injustice. While the opportunity and urgency for organizations to harness resources and leverage influence in addressing social injustice is clear, the pathways for organizations to become conduits of healing in society has been less so.

In this research, we explore how organizations can become healing spaces, and, in particular, serve as stewards and agents of social justice. We develop a conceptually grounded framework to examine organizational healing practices. We define healing as a restorative, transformative process of repair or recovery resulting in positive change, finding meaning, and movement towards self-realization of wholeness and greater strength (Firth et al. 2015; Powley and Piderit 2008). We advance insights about the possibility and importance of cultivating organizations as healing spaces - places in which individuals, dyads, and groups are supported by elements that can be resourced to facilitate and nurture healing (DuBose et al. 2018; Sakallaris et al. 2015). The scope of this research includes for-profit enterprises, with anticipated application to a variety of organizational forms. In structuring 
this paper, we first provide an overview of social justice in organizing contexts, followed by a consideration of healing in relation to organizations. Next, we identify a set of healing modalities that draws on four perspectives - restorative justice, posttraumatic growth, relational cultural theory, and dignity - in supporting healing at the individual, dyadic, organizational, and societal levels. We synthesize learnings from each modality to highlight distinct capabilities and practices for organizations to consider and adopt in responding to and resolving issues of social justice. Finally, we propose a typology of organizations as healing spaces, elaborate how healing can be cultivated in and by organizations, and discuss implications and opportunities for future investigation and practice.

\section{Justice \& Organizing}

The general concern of social justice is identifying and enacting what is fair, equitable, and right for members of society. While there is no widely agreed upon definition or interpretation of social justice (Kechen 2013), social justice is fundamentally about "justice among people" (United Nations 2006: 9), where justice refers to the quality of being fair and in conformity with what is morally upright or good (Merriam-Webster's Collegiate Dictionary 2021). Broadly, social justice can be understood as a concept that encompasses the premise of human equality and principle of fairness in the context of rights, opportunities, and treatment of people regardless of social category. Social justice is 'holistic' and 'systemic' (Miller 2017), involving adherence to the fair and equitable treatment of people and in relationship with sociopolitical institutions.

The seeds of Western social justice discourse have grown from ancient Greek considerations of justice, i.e., "to each their due," or, that people receive what they deserve, and, that how people are treated matters (Miller 2017). The modern-day language and conceptualization of social justice emerged out of the industrial revolution with philosophers' (e.g., Proudhon, 1809-1865) concerns over increasing economic disparity and ramifications for the human condition (c.f., Harbold 1969). Social justice considerations developed further and more formally following the Second World War (Tyler et al. 1997) as the social sciences of economics, psychology, and sociology grew and diverged both from each other and from the discipline and moral considerations of philosophy (United Nations 2006). Given its roots in income disparities, rights violations, and calls for reform associated with the rise of industrial organization (Ornstein 2017), mainstream management and organizational scholarship has directed substantial attention to understanding the consequences of experienced injustice by organizational members and the actions that organizations and their leaders can take to minimize the subjective injustices experienced by their members in the context of their work lives (e.g., Cropanzano and Ambrose 2015; Greenberg \& Colquitt, 2005).

Robust streams of social justice literature exist in sociology, philosophy and political science, psychology, and education (c.f., respectively: Romero 2020; Barry 2005; Tyler et al. 1997; Mills and Ballantyne 2016), among other domains of modern scholarship. Notably, calls for social justice are typically informed and motivated by experiences and perceptions of its absence. Social injustice encompasses the structural or cultural perpetuation of inequity based on race, gender, sexual identity, age, physical ability, cognitive profile, or other instantiations that influence unfair treatment and the impoverishment of human rights and dignity. Contemporary social justice issues are complex, structurally and culturally embedded, and enduring (c.f., Hammack 2018). Social injustice 
ranges from common discriminatory treatment to human rights violations, and is entangled with and compounded by unequal access to economic, political, legal and educational resources including employment, healthcare, and housing among others. Addressing social injustice requires a comprehensive and holistic approach.

While the field of business and organizing - comprised of scholars, educators, practitioners, and extending to the broader ecosystem of stakeholders - has devoted decades of attention to understanding the subjective justice experiences of employees at work, less attention has been given to recognizing and remedying the deep, systemic inequities and injustices of modern society, including their pernicious roots in power, privilege, and prejudice. In their recent study of social justice attitudes and perceptions, Cartabuke et al. (2019: 606) assert: "There exists a need to enhance sensitivity toward social justice among firms, their managers, and employees and to reflect such sensitivity in policy and practice." Indeed, today's organizations are uniquely positioned and have a timely opportunity to advance the healing of social injustice across society.

Yet in the dominant literature streams of management and organizations, embracing opportunities for advancing a more socially just world, empowering social justice action and actors, and elevating the priority of social justice have lagged as explicit topics of research and discourse. In general, beyond a relatively narrow and largely philosophical band of consideration that has surfaced through the literature of business ethics (e.g., Murnion 1989; Samar 1999), as well as a concern for perceptions of justice in terms of employee-organization relations, i.e., organizational justice (e.g., Cropanzano and Rupp 2008, Greenberg \& Colquitt 2013), a sharp and sustained focus on remedying issues of, damage from, or threats to social justice has been largely lacking in organizational scholarship to date. Importantly, considerations of social justice are not missing altogether in management scholarship; themes of fairness and equity are often implicit underlying concerns in this research. For example, social justice underlies research streams such as racial or gender representation and other considerations of diversity in work and organizations (e.g., Ashcraft 2013; Brush 1999; Nkomo et al. 2019), as well as the social responsibility of organizations (Matten and Moon 2008) and environmental sustainability (Shrivastava 1995).

Notably, central aspects of social justice are already being explored - though not consistently identified as such - in management research. For example, Greenbaum et al. (2020) emphasize the importance of employees' ability to voice - and by extension to enact - their moral concerns, and note associated implications for advancing social justice in organizations. Social entrepreneurship and social innovation scholars explore how individuals and organizations are remedying specific social justice challenges by offering products, services, and innovations in both traditional and novel manners (c.f., Bornstein 2007; Marquis 2020). The recently introduced concept of corporate social justice (CSJ) is positioned as a reframing of corporate social responsibility (CSR), with a focus on healthy and mutually beneficial relationships among corporations and disadvantaged or harmed stakeholders (Zheng 2020). We anticipate that emerging research connected with our collective recovery from the COVID-19 pandemic and associated disruptions will take more specific account of negative consequences experienced disproportionately by different social groups of employees. While these pockets of attention are encouraging, the growth opportunity for social justice research and application in organizational scholarship remains significant. Most considerations of social justice in the organizational literature focus on addressing problems that exist within the organization system as opposed to larger scale societal interactions, institutional reform, or systems transformation. In contrast, our research aims to advance a view of social justice as an actionable horizon that extends both 
within and beyond organizational boundaries in making an important and timely contribution to societal healing and transformation.

\section{Healing and Organizations}

Healing is a restorative, transformative process designed to return an organism back to health from an unbalanced, damaged or unervated condition while also strengthening the organism. In contrast to a definitive end state in which a condition is considered "cured", healing represents an ongoing journey with many possible routes (DuBose et al. 2018). Inspired by healing as a biological process, management scholars have begun to explore the process of organizational healing. According to Powley and Piderit (2008: 137), organizational healing involves immediate repair and subsequent strengthening; that is, "it involves movement away from a wounded state toward a condition of strength" in preparation for long-term organizational recovery. In the same vein, Sisodia and Gelb (2019) explored multiple organizations devoted to healing and concluded that organizational healing represents an organizational quest to alleviate suffering and elevate joy.

Initial work on organizational healing focused on organizations' capacity to recover from crisis or trauma imposed on an organization by external shocks. For example, Powley and Piderit (2008) explored the process of organizational healing after a shooting incident in a Midwestern university. Likewise, Powley (2013) studied the processes by which the Prudential Real Estate company was able to heal after the housing market crashed in 2008 through its commitment to repairing practices, routines, and structures and to strengthening organizational functioning through social relationships. Both cases of healing involved repairing and mending the collective social fabric of an organization after a crisis caused by an external unexpected jolt.

An additional stream of research has explored organizational healing in the face of trauma caused by internal sources within an organization. In contrast to contexts of external jolts that are often outside of organizational control, this scholarship considers trauma that unfolds within organizational boundaries and is often incurred by organizational leadership, culture and/or practices that enable harm, wrongdoing, incivility, or discrimination. For example, Clark (2012) studied bullying and incivility exhibited toward minority nurses and other health professionals in nursing schools, hospitals, and private practices to unpack how healing from such experiences can be brought to life in these organizational contexts. Porath and Pearson (2012) examined the emotional and behavioral response to incivility at work and called attention to the role of organizations in developing greater awareness about the harmful effects of fear and sadness caused by incivility in the workplace. De Maria (2010) studied how organizations attempt to recover from scandals after public exposure and identified three different types of responses (e.g., 'redemptive', 'tread water' and 'rogue') that organizations adopt.

This body of work uncovers several critical assumptions. First, in contrast to resilience, coping, or recovery that represent positive adjustment processes designed to maintain a previous equilibrium state (Luthar et al. 2000) or to return to normalcy (Bonanno 2004; Lilius 2012) in the face of adversity, healing represents the development of organizational strength in excess of what previously existed. Second, recent organizational research reveals healing as a quest (Sisodia and Gelb 2019) that reflects an ongoing organizational commitment to healing rather than an end state. This depiction of healing work is important as it turns our attention to the continual learning involved in healing and the social architecture 
that can awaken ongoing healing processes (Worline and Dutton 2017). Third, while most organizational healing research focuses on healing in response to harm experienced within the organizational boundaries, recent work on organizational healing has begun to explore the role of organizations in healing outside the boundaries of organizations. This approach positions businesses as a place of healing for employees and their families, a source of healing for customers, communities, and ecosystems, and a force of healing in society (Sisodia and Gelb 2019). This research redefines for whom organizations are responsible and how organizations might contribute across the broader spectrum of societal healing. Next, we turn to discuss healing modalities and illuminate practices at the heart of healing.

\section{Healing Modalities}

Crafting organizations as healing spaces requires organizations to develop distinct capabilities and practices. To identify practices that can facilitate healing in and by organizations we spotlight insights from clinical psychology, social psychology, and conflict resolution research that can help unpack opportunities and steps for shaping organizations as healing spaces. More specifically, we draw on four perspectives that address healing in organizational contexts: (1) restorative justice, (2) posttraumatic growth, (3) relational cultural theory, and (4) dignity - all of which represent prominent perspectives exploring how healing can be pursued at the individual, dyadic, organizational, and societal levels. Below we offer brief summaries of these perspectives and associated practices for healing. We use integrated insights gleaned from these approaches as a foundation for the typology we propose in the subsequent section of the paper.

\section{Restorative Justice}

Restorative justice emerged in the 1970s in response to critiques that the Western legal approach to crime fails both victims and perpetrators (e.g., Braithwaite 1999; Zehr 1990, 2002). Specifically, the restorative justice approach seeks not merely to punish wrongdoers, but also to provide opportunities for victims to describe their experiences and shape the punishment, and for offenders to take responsibility for their actions and their consequences on victims and the community (Zehr 2002). Thus, beyond addressing an offense and paired consequence, the restorative justice approach focuses on "healing and reintegration for all" parties to a justice violation (Goodstein \& Aquino 2010: 625). This perspective tends to prioritize processual interactions in parallel with the goal of comprehensive healing outcomes.

The restorative justice approach requires active participation of victims, offenders, and the community in devising a healing response to the harm (Goodstein and Aquino 2010). In a restorative justice conference, victims and harm-doers, along with friends, family, and other community members, meet face-to-face and engage in supported dialogic communication (Borton and Paul 2015; Zehr 2009). In dialogic communication, parties discuss the present and past behavior and experiences, as well as their future goals, using a series of practices including listening, storytelling, perspective-taking, and emotion sharing (Black 2008; Umbreit et al. 2007; Zehr 2002).

Central to the effectiveness of this model is reintegrative shaming, in which victims and the community can express their disapproval of the offender's actions while communicating their respect for and forgiveness of the offender (Braithwaite 2002). Furthermore, 
offenders are expected to accept responsibility and apologize for their transgressions, thereby restoring their own dignity and allowing them to reconnect with their community (Tyler 2006).

Successful restorative justice processes can heal all parties: victims, offenders, and the community "through both material and symbolic restitution, rebuilding the self-respect of offenders, and integrating them back into the community" (Goodstein and Aquino 2010: 625; Braithwaite 2002; Wenzel et al. 2008). Restorative justice provides psychological benefits to victims and offenders in the form of greater empowerment (Armour and Umbreit 2006; Braithwaite 2002; Morris 2002) and psychological growth (Borton and Paul 2015). Victims also report less fear, desire for revenge, and posttraumatic stress (Sherman et al. 2015). Restorative justice also can repair the relationship between the offender and victim and the offender and community (Fehr and Gelfand 2012). Finally, restorative justice heals the community by reducing recidivism and ongoing cycles of harm (Sherman et al. 2015) and by reaffirming important social values (e.g., Block 2009; Wenzel et al. 2008).

\section{Posttraumatic Growth}

Posttraumatic growth is a psychological theory that illuminates a trauma-based account of growth from "shattered assumptions" (Tedeschi and Calhoun 2004). Posttraumatic growth refers to a transformative positive change that can follow an adverse event (Linley and Joseph 2004; Maitlis 2011). This perspective frames healing as an outcome (e.g., Calhoun \& Tedeschi 2006; Janoff-Bulman 2006) or a process (e.g., Affleck and Tennen 1996; Nolen-Hoeksema and Davis 2004). Healing, according to this perspective, centers around meaning making or reframing processes involving change in (a) perceptions of self, (b) relationships with others, and (c) philosophy of life designed to derive strength from setbacks.

Most of the posttraumatic growth literature focuses on healing an individual. This line of research proposes that individuals can be traumatized by intense negative and unexpected events (Janoff-Bulman 1992; Linley and Joseph 2004; Tedeschi and Calhoun 2004) that can shatter one's assumptive world (Maitlis 2011) or shift an individual's meaning systems (Park 2010). According to the posttraumatic growth perspective, healing unfolds through meaning making processes designed to rebuild one's foundational assumptions or beliefs about the world (Maitlis 2011). A central part of process models of posttraumatic growth is the notion of accommodation. Tedeschi and Calhoun's $(1995,2004)$ functionaldescriptive model suggests healing can occur when survivors accommodate their trauma. This involves survivors moving from trying to explain what has happened to them to establishing whether and how they can deal with it, and ultimately to making sense of the trauma while acknowledging its positive meaning and future possibilities. Likewise, Joseph and Linley's (2005) organismic valuing model proposes that healing comes as survivors revise their schemas to accommodate (e.g., "sometimes bad things happen to good people") rather than assimilate (e.g., "bad things happen to bad people") the trauma into their existing models of the world and self.

The literature on posttraumatic growth highlights two mechanisms that can enable healing of individuals: disclosure and social support. First, Tedeschi and Calhoun (1995, 2004) emphasize the importance of disclosing thoughts and feelings to others as a critical mechanism of posttraumatic growth and healing. The intentional sharing of one's own current or past traumatic experiences to either seek help or share one's personal history with trusted others have been found to positively relate to growth and recovery (Frey and 
Fulginiti 2017; Frey et al. 2020). Second, although growth and healing are achieved by individuals who reframe the way they think about themselves, their relationships with others, and the world, others also play a critical role in this process. According to this perspective, supportive interactions with others are essential for growth and healing (Tedeschi and Calhoun 2004). Social support can help individuals develop positive accommodations of their trauma and change the meaning survivors accord to their lives and relationships to acknowledge unique possibilities and strength (Linley and Joseph 2004). In contrast, social contexts that are not supportive can lead to negative accommodations and feelings of helplessness by survivors.

Posttraumatic growth also points to practices that can support organizational healing processes (Powley 2013; Powley and Piderit 2008). Healing, at the organizational level, involves repair and strengthening work designed to help organizations recover from a local crisis and expand organizational ability to withstand future crises (Kalfas 2001; Schilling 1968). This line of research proposes that healing processes involve three sequential phases: protective inflammation, relational proliferation, and remodeling (Powley 2013; Powley and Piderit 2008). Protective inflammation represents an activation phase in which resources are mobilized to the wound site to stabilize the trauma, mitigate potential harm, and prepare the wound site for future growth. This entails actions taken by organizational leaders and members who deploy social, organizational, and material resources to stabilize organizational performance and protect against potential threats. At this stage, organizational leaders and members who feel called to deal with the organizational crisis aim to generate an organizational-wide positive energy to support crisis response and to secure the collective well-being of organizational members. This attempt to restore group efficacy is achieved by substantive actions (e.g., invoking policies and procedures to prevent further loss) and symbolic actions (e.g., reinforcing the organization's vision and culture).

Whereas protective inflammation is designed to mobilize resources to tend to the local wound, the relational proliferation that follows is designed to propel growth and strengthening of the organizational tissue. This entails organizational members identifying, building, and strengthening key internal and external relationships that support the overall organizational recovery. Relational proliferation is achieved through positive relationships and high-quality connections (Dutton and Heaphy 2003) and social support (Fazio and Fazio 2005) in which organizational members come together to form bonds and connect emotionally (Mooney 2009), strengthen ties, and foster cohesion between organization members. As inflammation ebbs and the network of supportive relationships grows, organizations are ushered toward the last phase of healing, termed remodeling. Remodeling involves not only returning to the previous organizational state and function but also generating additional core strength that protects the organization against future potential harm (Mitchell 1996; Powley 2013; Powley and Piderit 2008). This phase entails organizational members strengthening family-like bonds and initiating ceremonies and rituals that create a sense of closure and renewal (Powley and Piderit 2008). As in physiological healing, optimal healing occurs through successive stages and may be compromised if the order of steps is changed or if phases are omitted. Thus, this perspective posits that organizational healing will be achieved only when all three phases are completed.

Researchers exploring the mechanisms underlying the organizational ability to heal from external crises propose four mechanisms enabling organizational healing, including empathy, healing interventions, collective effort, and leadership (Powley 2013). Empathy refers to individuals' ability to understand another's point of view and emotionally relate to others' experiences (Batson et al. 1996). Empathy seeds and nurtures positive relationships with others in the organization that plays a central role in relational proliferation. Healing 
interventions pertain to the deployment of internal resources and access to external support that can help protect against fear and intimidation, stimulate social processes, and enable growth and rebuilding (Powley 2013). Internal interventions often include actions that rebuild social connection after external disruption. External support may include networked stakeholders coming to the organization's aid, client engagement meetings, or newly recruited leadership marshalled to reinforce the organizational attempt to recover from the crisis at hand. Collective effort captures the extent to which organizational members strongly identify with the organization, its mission, and vision, which in turn translates to collective effort to resume and reinforce organizational processes that further strengthen the organization. Collective efforts are especially critical during relational proliferation and remodeling phases of organizational healing as such efforts help maintain order as organization members act together to reproduce necessary organizational structures and routines. Leadership also plays a critical role in enabling organizational healing. During the protective inflammation stage, leaders offer clarity about their intention and direction of the organization in crisis, prioritizing needs, deploying resources, and inspiring a positive vision. During the relational proliferation phase, leaders seed and promote a positive energy network of internal and external stakeholders in an effort to build trust and mobilize a wide range of individuals to join this cause. Finally, during remodeling leaders create opportunities to strengthen the organizational culture and enhance the sense of purpose and meaning of those involved.

\section{Relational Cultural Theory}

Relational cultural theory (RCT) originally emerged as a feminist theory that aligns with multicultural movements in psychology and embraces many aspects of social justice. RCT (Miller 1976; Jordan et al. 1991; Miller and Stiver 1997) unpacks the conditions that bring about healing and sheds light on microprocesses of social interactions embedded in the larger societal contexts of gender and power dynamics that are at the heart of healing processes. In contrast to Western models of adult development that envision growth as a process of becoming increasingly proficient at separating and individuating oneself from others as one moves from dependence to independence, RCT proposes that growth and healing happen when we are in connection with others (Miller 1976; Miller and Stiver 1997; Surrey 1985). RCT recasts the goal of relationships by suggesting that connection with others does not hold us back from growth or healing; rather, positive relationships usher individuals toward increased competence in enacting both members' self-in-relation and increased ability to operate effectively in a context of interdependence (Fletcher and Ragins 2007).

Importantly, RCT does not suggest that all relationships are positive. This perspective is often utilized in response to experiences of disconnections and disrupted relationships, and illuminates relational qualities at the heart of a healing connection (Miller and Stiver 1997). According to RCT, healing connections are characterized by mutuality, in which the boundary between one's self and one's partner is fluid and multidirectional (Fletcher and Ragins 2007). This process involves two individuals moving first toward mutual authenticity (bringing one's authentic self to the interaction), then to mutual empathy (whereby one can hold onto one's self but also emotionally relate to the experience of the other's reality), and finally to mutual empowerment (whereby each person is in some way influenced or affected by the other, so that something new is created) (Jordan 1997; Jordan et al. 1991). A second relational quality of healing connections stems from the power dynamic evident 
in such relationships. In contrast to hierarchical, top-down relationships in which one individual has power over the other, the power dynamic experienced in healing connections reflects power with others, enabling both parties to meaningfully shape the relationship and co-participate in the growth and healing processes (Kabadayi et al. 2019). According to RCT, a key condition for healing connection is that participants approach the interaction expecting to grow and be changed by it, and feel a responsibility and desire to contribute to the growth and healing of the other. More specifically, relational cultural scholars point to the importance of relational skills such as empathy, listening, and emotional competence as essential building blocks to enable healing in connection (Fletcher 1999).

\section{Dignity}

Dr. Donna Hicks, an esteemed international conflict resolution scholar, has written extensively about the role of dignity in perpetuating a sense of well-being and in healing both organizational and national conflicts. Hicks defines dignity as "an internal state of peace that comes with the recognition and acceptance of the value and vulnerability of all living things" (2011: 1). A central premise of this work is that progress toward improved relationships and healing necessitates the recognition of suffering; indignities, or dignity violations, must be named and acknowledged, and then redressed (2011: xiii). Threats to dignity are experienced as injuries to well-being and require comprehensive engagement (vs. disengagement) and empathy (vs. aggression) to be remedied. Her framework details ten essential elements of dignity, including virtues and conditions necessary for healthy relationships and reconciliation: acceptance of identity, recognition, acknowledgement, inclusion, safety, fairness, independence, understanding, benefit of the doubt, and accountability (2011: 25-26; 2018). This framework has been used for the last two decades as the basis of large-scale conflict resolution across the globe in Europe, the Middle East, and South America. It seeks to address the physical and psychological pain caused by others and the impacts on both individuals and identity groups through a reconciliation approach.

The first three dignity elements can be understood as setting the groundwork for co-creating a space in which reconciliation and healing can occur. Acceptance of identity ensures actors that they are viewed and will be treated as equals, and that who they are at their core is accepted and may be fully expressed. Inclusion invites and embraces a sense of belonging in the relationship. Safety is essential for putting actors at ease physically and psychologically so they can communicate freely and without fear. The next four elements are activated through dialog, listening, and behavior in the process of healing dignity violations. Acknowledgement entails full attention, validation, and responsiveness to actors' concerns and experiences. Recognition involves appreciation and gratitude for efforts and contributions in the reconciliation process. Fairness upholds standards of law or rules, justice, and equality, and protects against discrimination and injustice. Benefit of the doubt establishes the premise of trustworthiness, good motives, and integrity among actors. Understanding encourages sharing, explaining, openness to, and deep listening toward all points of view. The last two elements encourage agency and responsibility-taking by actors. Independence supports a sense of hope and possibility based on actors' experience of control over their own well-being. Accountability demands that actors hold themselves and each other responsible for incurring and rectifying injury.

For reconciliation within this dignity framework, healing occurs when all parties take a key action and simultaneously support three fundamental human needs. The first step is 
"public acknowledgment - no reconciliation and healing are possible without acknowledging the lived experiences and truth as experienced by both sides" (Hicks 2011: 188). Support for this process entails that all involved recognize the need for safety and nurturing by cultivating an environment in which parties can share their past experiences. To address the need for control, programs should strive to give back power to parties. Finally, with these two conditions leaders can encourage authentic and vulnerable sharing to foster reconciliation (Hicks 2011: 190).

This acknowledgement process and the ten essential elements of dignity highlight the role of empathy, also identified by the RCT and restorative justice. In addition, vulnerability and humanizing others and self are seen as critical components of the healing process. The pathway to healing from the lens of dignity is reconciliation to honor each other's inherent self-worth.

\section{Integrated Insights}

Each of these modalities of healing described above share important parallels. Table 1 compares and contrasts these perspectives that we use as a foundation for our theorizing.

All the healing modalities we review acknowledge healing as a social and relational process that requires authentic and mutual involvement in collective efforts toward restoration and renewal. Broadly, these healing modalities involve restoration of well-being, which is applicable at micro-, macro-, and blended levels of analysis, and recognizes both mending and safe-keeping of self as well as restoration, growth, and strengthening of relationships. Healing processes include active participation by those who have experienced injury or injustice and by those who have caused harm or suffering - and often by both together. Vulnerability is central in healing, including the willingness to share experiences of pain and trauma, as well as the ability to listen to, accept, and understand accounts shared by others. Empathy, in terms of activating compassionate understanding and the ability to relate to oneself and others, is another central capability across practices of healing.

These modalities highlight the importance of surfacing, engaging, and validating multiple perspectives of injury, pain, or trauma in processes of healing. Acknowledgement of harm, along with recognition of how the injury or injustice has been created or reproduced (whether intentionally or unintentionally), are critical foundations for healing. In addition, these modalities suggest that dedicated roles can help to facilitate healing, including the involvement of leaders or facilitators who are tasked with and trained to steward healthy progress. Finally, healing may be understood as restorative for all (not just for victims), and as enabling the possibility for deeper connections and more generative relationships across contexts.

\section{Organizations as Healing Spaces Typology}

Our observation is that contemporary organizations - and increasingly for-profit enterprises - are being called upon to cultivate healing spaces. In this section of the paper we build and extend extant literature on healing reviewed above and argue that the cultivation of healing within and by organizations can be categorized into three qualitatively different responses. The typology we propose illuminates these three spaces of healing - emergent, endeavoring, and exemplifying. Each healing space may be characterized and differentiated across several dimensions, including: source of harm as prompt for healing, recipients and 


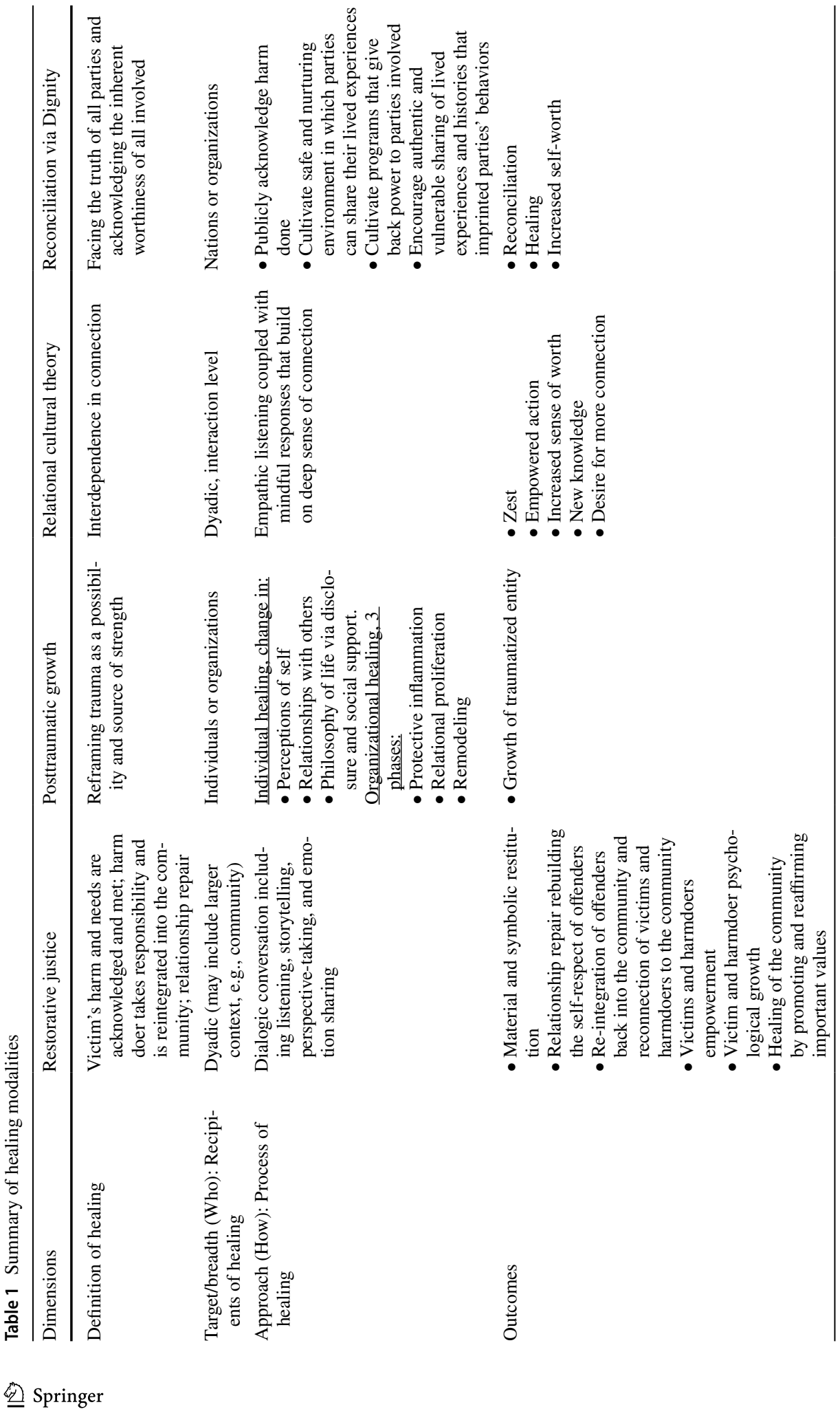




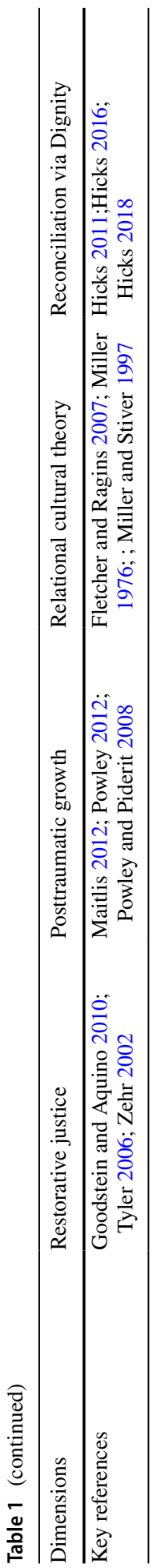


agents of healing, focus of healing, duration and intensity of healing, and processes and practices of healing in and of organizations. See Table 2. These sets of healing responses are neither comprehensive nor exclusively discrete, but instead provide a broad framework for understanding generalized roles, reasons, and resources for organizational leaders and members to be better equipped to foster healing capacities and cultivate organizations as healing spaces.

\section{Emergent Healing Space - Healing Approach to Localized Harm Caused by External Jolt Outside of the Organization's Control}

In emergent spaces of healing, organizations focus on recovering from external shocks, typically from a one-off event such as a natural disaster (earthquake, tsunami, or similar events) or human disaster (terrorism, war or other human-driven catastrophes), representing extreme jolts outside of an organization's control (e.g., Powley and Piderit 2008; Powley 2012). In such crisis situations, it is typically leaders and other experts, governmental or otherwise, who dictate the healing response with swift decision-making and policy-setting in reaction to the event. This approach often represents a reactive realization paired with responses targeted internally and focused on the immediate local "wound," such as relief efforts for employees directly impacted by an external crisis, including resources such as time off, supplies, and financial support. This organizational healing space may extend beyond the organization's structural boundary in terms of the provision of relevant services, donations, and expertise to alleviate suffering and help strengthen local communities.

For example, H-E-B, a privately held grocery retailer based in San Antonio, has a long history of dealing with natural disasters within its service region. When Hurricane Harvey presented a challenge of unprecedented magnitude, many H-E-B employees were displaced by the extreme weather incident and could not get to work. H-E-B deployed helicopters to fly truck drivers in from San Antonio, so they could move delivery trucks out of the yard to rescue displaced employees (Sisodia and Gelb 2019). Moreover, in its effort to support H-E-B employees and to serve local communities under the most duress, H-E-B activated its network and called for volunteers to assist understaffed stores. In turn, more than 2000 community partners from Austin, San Antonio, the Rio Grande Valley, and other locations answered the company's call for help (Sisodia and Gelb 2019).

In this emergent healing space, the need for quick action and unilateral decisions is dominant. Organizational attention tends to be immediate and temporary in response to external shocks causing harm to organizational members and their immediate communities. Healing occurs through empathy (Hicks 2011; Powley 2013) for experienced misfortune and through collective efforts (Powley 2013) to mobilize monetary and relational resources to address the local, emerging needs often championed by organizational leaders (Powley 2012). Importantly, some organizational responses in the emergent space may consist of symbolic action, such as internal or public statements expressing support, or the amplification of relevant organizational vision and culture (Powley and Piderit 2008). However, healing may not occur unless symbolic action is coupled with substantive action (Powley and Piderit 2008), which privileges policies, procedures, and the mobilization of resources to address local needs of those directly harmed.

Scholars examining how organizations recover from external unforeseen crises outside of their control (e.g., local fire; Dutton et al. 2006) emphasize the importance of relational 


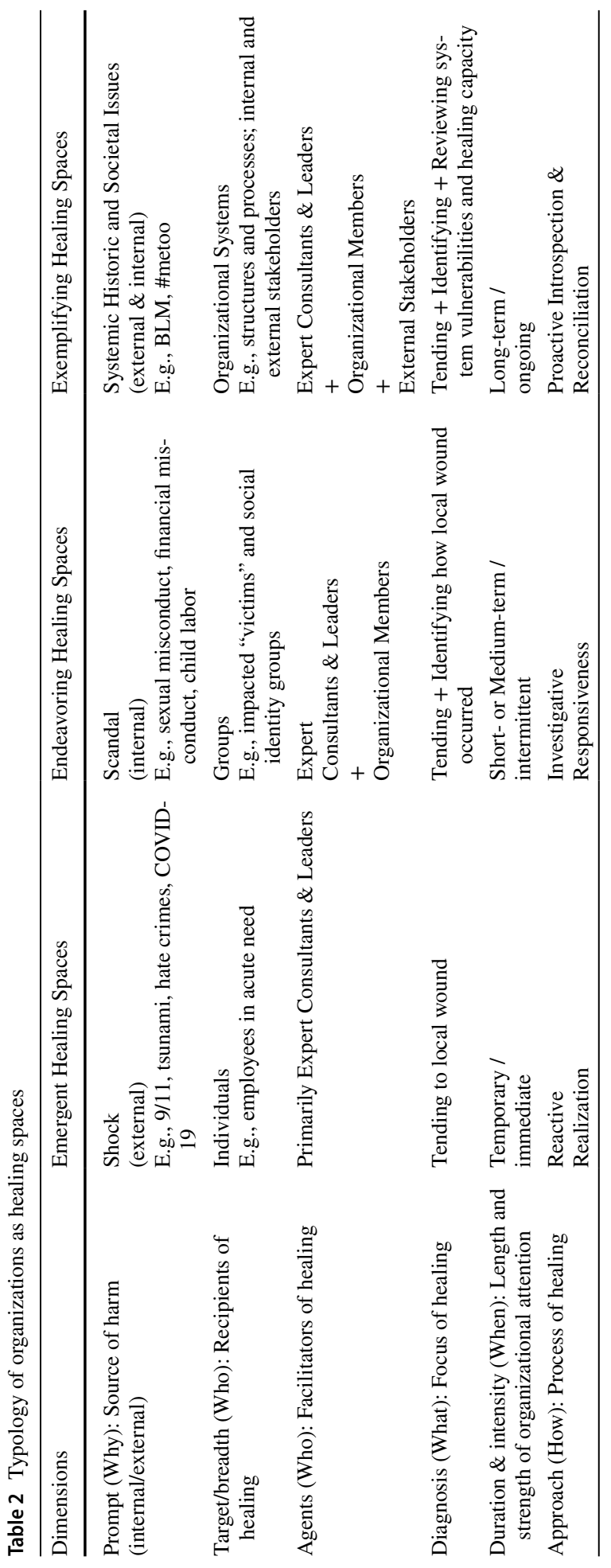




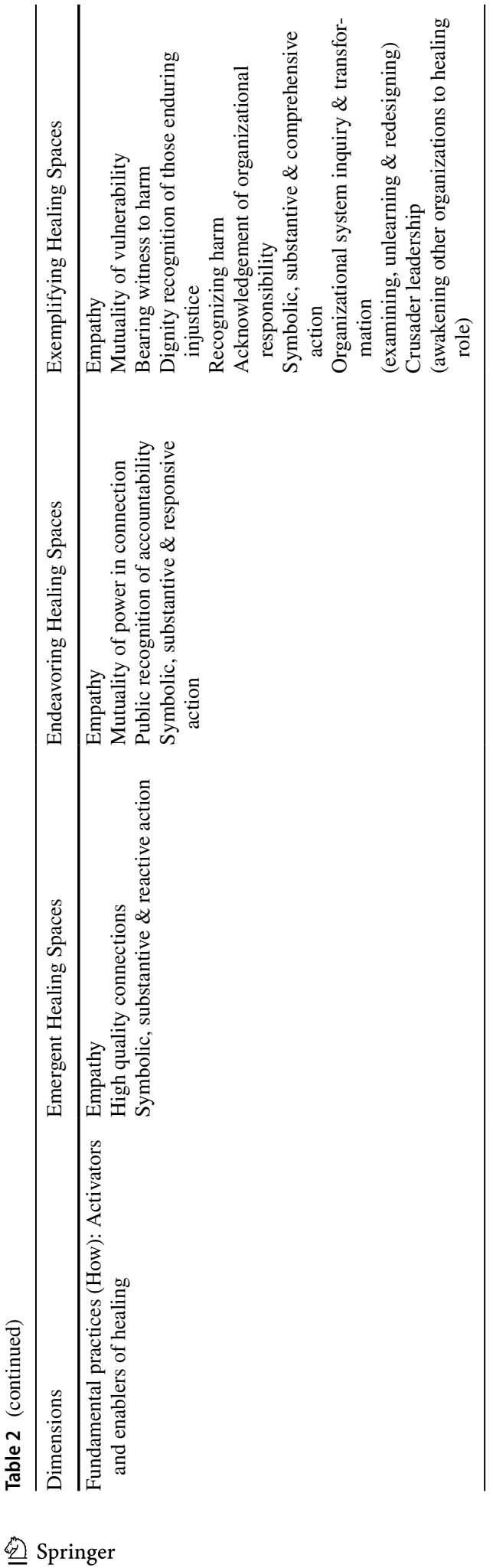


proliferation. This notion captures the capacity of organizational members to cultivate high quality connections within the organization that help to rapidly expand support networks that can be resourced for responding to local needs (Powley and Piderit 2008; Dutton et al. 2006). Importantly, such healing efforts not only offer relief to the immediate needs of organizational members, but also sharpen organizational capacity to address future unforeseen external jolts impacting others within the organization (Dutton et al. 2006) and expand the organizational capability to recover from such strains in the future (Powley 2013; Powley and Piderit 2008). It is worth noting that some organizational members might question support actions due to the sentiment that these roles and functions are best served by the public and not private sector organizations, what some behavioral ethicists term "denial of responsibility" (Anand et al. 2004).

\section{Endeavoring Healing Space - Healing Approach to Localized Harm Created by Organizations or Their Members}

Endeavoring spaces of healing encompass an organizational commitment to working toward typically localized healing from harm caused by sources within the organization's boundaries and control. In contrast to the emerging space, where organizations notice and react to harm caused by external jolts, in an endeavoring healing space organizations demonstrate growing awareness of harm caused by organizational members and other internal stakeholders within the organization's control and responsibility (e.g., sexual harassment; discriminatory practices; unethical decision-making; problems precipitated by operations, products, or services). This space is characterized by organizational efforts to notice and respond to harm that exists and occurs within the organization, including suffering resulting from psychological, physical, or ethical violations perpetrated by organizational members.

Similar to the emerging space, in the endeavoring space organizations also respond to acute symptoms of harm and focus healing efforts on recovery from experienced suffering. Beyond the largely reactive response that characterizes healing in the emerging space, the process of healing in the endeavoring space typically includes a focus on investigation to identify how harm occurs as well as what course of action is needed to remedy associated suffering and address evident organizational causes. In this space, healing is typically initiated when a visible tipping point is reached, such as when a report is filed, a petition is registered formally, or an incident is publicized. Importantly, this space of healing is facilitated by a sense of physical and psychological safety (c.f., Edmondson 2018) that reinforces transparent and honest reporting as well as freedom from fear of retribution (Hicks 2011) that victims or whistleblowers frequently negotiate in illuminating situations of suffering.

In an endeavoring space of healing, recipients of healing are individual organizational members (i.e., "victims") and/or potentially those social identity groups most directly impacted by the violation (i.e., Asian employees in the case of anti-Asian aggression and hate speech). Healing is enabled when all parties involved (victims and transgressors, organizational leaders, and organizational members, including Human Resource professionals and Diversity, Equity \& Inclusion [DEI] officers) take an active part in the process of remediating the situation so that power is shared in a way that enables mutuality (i.e., every party is welcomed and encouraged to participate in this process, albeit in different forms [c.f., Miller and Stiver 1997; Hicks 2011]). If the chasm between victims and transgressors is too great to bridge with internal resources, external experts and consultants, 
employees advocates or stewards, and other DEI specialists may be called upon to facilitate and cultivate a safe space in which empathic listening is practiced and dialogic communication is enabled (Tyler 2006).

A central activator in an endeavoring space of healing pertains to the organizational recognition of the harm and public acknowledgement of organization's accountability (Hicks 2011; Tyler 2006). This often entails public apology, coupled with symbolic as well as substantive action to repair damage and meaningfully address the causes of harm. For example, a 2020 campaign supported by over 1500 Cass Business School students and staff members called the attention of their institution, City, University of London, to the harm caused by commemorating Sir John Cass. Cass was a major figure in the early development of the slave trade and the Atlantic slave economy, and a historical symbol of racist and inhumane actions and the institutionalization of racism. ${ }^{1}$ In response, the Business School acknowledged the harm caused by designating this name for the business school and publicly committed to changing its name in an effort to reject an organizational identity associated with the slave trade.

In an effort to address student and staff concerns, the institution launched a comprehensive inquiry and consultation process with stakeholders, and invited the university community to suggest alternative names for the business school. Over 8000 participants - including staff, current and prospective business school students, and alumni-participated in this process. Approximately 150 new names were proposed for the business school; Thomas Bayes emerged as the leading choice. Bayes (1702-1761), a nonconformist theologian and mathematician, is best known for Bayes' theorem, which proposes that we get closer to the truth by constantly updating our beliefs in proportion to the weight of new evidence. City sources ${ }^{2}$ indicated that it is this idea - not only the person - that served as the motivation behind adopting the new name for the business school, Bayes Business School. As this example illustrates, the university demonstrated openness to bear witness to suffering experienced by stakeholders in association with historical institutional connections to slavery and racism, publicly acknowledged harm and complicity in perpetuating suffering through controversial naming conventions, proactively involved multiple stakeholders, and generated responsive symbolic action (e.g., renaming the business school, implemented September $2021^{3}$ ) in an initial effort to propel future substantive action in cultivating further healing.

Another example of what could be characterized as an endeavoring space of healing in and by organizations involves the issue of child labor across global supply chains. Firms spanning fashion and apparel, cosmetics, manufacturing, consumer goods, and food and beverage industries have become more attuned to social issues related to the illegal employment of children, largely in response to public scrutiny and regulatory pressure. For example, in 2007, the apparel manufacturer and retailer Gap became embroiled in a scandal involving an Indian supplier's violation of child labor laws and Gap's stated operating standards. When these exploitative working conditions were exposed, the company responded by immediately acknowledging its supplier's wrongdoing and accepting

\footnotetext{
1 https://www.change.org/p/city-university-of-london-city-university-rename-cass-business-school-origi nally-named-after-a-slave-trader

${ }^{2}$ https://www.cass.city.ac.uk/news-and-events/news/2021/april/the-business-school-formerly-cass-to-berenamed-bayes-business-school\#: :text=The $\% 20$ Business $\% 20$ School $\% 20$ (formerly $\% 20$ Cass) $\% 20$ will $\% 20$ be $\% 20$ renamed $\% 20$ as $\% 20$

3 https://www.bayes.city.ac.uk/about/more/our-name-change
} 
responsibility in working to address and rectify the situation for each child involved in the incident and throughout its operations more broadly. Gap announced a package of measures to tighten its "commitment to eradicating the exploitation of children in the manufacture of its goods," including paying back wages, providing educational expenses, and offering employment at legal age to the children involved (c.f., Gentleman 2007).

In an effort to overcome and rectify harm to the child laborers exploited by the supplier, symbolic action included the Gap president's statement about the absolute unacceptability of child labor. This was followed by reports of substantive action, including: launching a full investigation; providing remuneration, education, and future job opportunities to the 14 children directly impacted; and, levying contract penalties in parallel with tightened operational oversight of the exploitative supplier. In addition, the company reportedly provided a significant grant to support work on improving working conditions in India, and initiated an international conference to focus on solutions for issues related to child labor. While an endeavoring space is not characterized as fundamentally holistic or systemic in its approach to or resources of healing, it does represent a space of important organizational effort and intention to meaningfully acknowledge and recognize suffering and injustice caused by or with the operating scope of the organization, to accept responsibility for overcoming such harm, and to address and remedy injury or injustice that is understood to lie within the direct and even indirect control of the organization. Importantly, in the endeavoring space a lack of substantive action toward taking responsibility and correcting mistakes made by an organization can stifle healing. In this space, perceptions that an organization's commitment to addressing harm is limited, lacks integrity, or is inauthentic (c.f., Maak 2008; Dare 2016; Steckler 2012, 2014) can derail healing.

\section{Exemplifying Healing Space - Holistic Healing Approach Within and Comprehensively Beyond Organizational Boundaries}

Exemplifying spaces of healing stand at the cutting-edge of the holistic, systemic healing potential of organizations. These spaces span private, public, and nongovernmental sectors, and are characterized by organizations actively working to address the broadest scope of healing of systemic harms endured by individuals and social groups both within and outside the boundaries of the organization. This healing space entails organization-wide attention to systemic historic and cultural issues, and the demonstration of deep engagement with resultant internal and external injustice and pain. The exemplifying space is characterized by organizational commitment to proactively address injustice as an integral part of the way organizations perceive their role in society. Whereas processes of healing are characterized in the emerging space as reactive to external shocks and in the endeavoring space as responsive to acute local wounds occurring within the organization's generalized scope of control, the exemplifying space reflects a proactive, comprehensive, and holistic approach toward healing by organizations.

This approach to holistic healing calls organizations to engage in introspection, including reviewing the systems and vulnerabilities that create and reproduce inequity, and challenging and reinventing organizational systems as paths toward healing. Organizations that function as exemplifying healing spaces activate healing by embracing the importance of vulnerability and adopting a beginner's mindset, akin to the notion of innocence and curiosity, in attempting to fully account for and understand multiple points of views among those impacted by societal injustices. Such organizations carve spaces for individuals to deeply bear witness to suffering by being fully present and to approach problems with 
humility, rather than prior assumptions, suspending any denial, rationalization, or opinion about another's experience of suffering. This kind of engagement with suffering affords the opportunity to approach a deeper familiarity with the lived experiences of suffering. This in turn seeds empathy toward those affected by societal injustices, and mobilizes organizational members to recognize harm endured by and act to restore the dignity of marginalized people.

While some of these elements are also demonstrated in emergent and endeavoring spaces, an important differentiator of an exemplifying space is that healing stems from the nature of actions undertaken by organizations. We propose that organizations embracing an exemplifying space of healing are characterized by their commitment to comprehensive inquiry to examine, unlearn, update, and redesign organizational practices, policies, and organizational roles that privilege healing as a primary organizational contribution. This enables organizational members to notice injustice within and outside the organization, acknowledge the organizational role and responsibility in healing what is broken in our society, take substantive actions to dismantle organizational structures, functions, and procedures that recreate, reinforce, and reproduce injustice, and invite diverse voices to contribute and co-create inclusive organizational systems that aim to cultivate and enhance justice and equity.

An example of an exemplifying space of healing is Greyston Bakery, a for-profit organization known as champion and advocate for Open Hiring. Greyston aims to lower unnecessary barriers of employment and to enable individuals who may be perceived by others as unemployable (e.g., previously incarcerated members of society) a chance at social mobility (Pirson and Livne-Tarandach 2020). Greyston's mission is human-centric - rather than hire individuals to bake brownies, the bakery aims to bake brownies to hire individuals. In doing so, Greyston cultivates an inclusive economy that innovates and expands rather than limits employment opportunities afforded to talented individuals who have been left on the sidelines (Pirson and Livne-Tarandach 2020). Greyston demonstrates a systemic approach that re-imagines the organization as a site of healing, cultivating organization systems rooted in mutual respect, dignity, and power shared with all involved. This entails the redesign of human resources practices (e.g., hiring without a traditional selection process), organizational roles (e.g., re-imagining the role of HR professionals and mentors, and creating new roles devoted to path-making for marginalized individuals), and policies (e.g., restructuring compassion and patience into organizational policies of employee' training, assessments, performance review, and promotion) to lower the barriers of employment, restore the dignity of marginalized individuals, and enable employee thriving within and outside the organizational boundaries. While such an approach may begin with an opportunity offered to an individual, it holds the potential to create far-reaching ripple effects. As Greyston's CEO and President Joseph Kenner remarks, such an opportunity also supports "a family that is embedded in the community and a broader society all of which are positively impacted by the opportunities enabled by Open Hiring" (Pirson and Livne-Tarandach 2020: 239).

Beyond their own commitment to promote justice within and outside the organizational boundaries, organizations as exemplifying spaces of healing are devoted to spreading a healing ministry. Such organizations often expand their circle of influence and demonstrate crusader-like leadership in awakening other organizations to consider their role in healing their local communities and our society. For example, Greyston is not only committed to serve as a healer of its local community, but is committed to educate and support other organizations (within and outside the US) to adopt Open Hiring as a path toward 
promoting social justice and expanding societal healing more broadly (Pirson and LivneTarandach 2020; Laasch et al. 2019).

While the benefits of organizational commitment to contribute as exemplifying healing space may be apparent and welcomed, some organizations may refrain from doing so and assume that such an approach may be unrealistic or unattainable for for-profit organizations (Laasch et al. 2019). Although such an approach positions profit and social good as a duality of two competing elements, recent research demonstrates the dualism of these elements and presents them as complementary such that socially responsible business centered around societal healing can in fact be profitable (Sisodia and Gelb 2019; Marquis 2020).

\section{Discussion}

Our paper offers a holistic definition of healing as the foundation for a new conceptual model of organizations as healing spaces. We draw upon four perspectives which address healing at various levels of analysis: (1) restorative justice, (2) posttraumatic growth, (3) relational cultural theory, and (4) dignity to develop a typology that illustrates three ways organizations can function as healing spaces - Emergent, Endeavoring, and Exemplifying. Overall, our conceptualization of organizations as healing spaces makes several contributions to the fields of healing and social justice research and offers a generative foundation for future theoretical and empirical work on healing and practical implications for organizational leaders and human resource managers, as well as for diversity, equity and inclusion (DEI) and corporate social responsibility (CSR) contexts.

\section{Theoretical Contributions to Healing Research}

In this paper, we build and extend the study of healing in organizational contexts in a number of ways. First, in contrast to "bounce back" approaches to healing that have focused largely on resilience, coping, or recovery as positive adjustment processes designed to maintain a previous equilibrium state (Luthar et al. 2000) or return to normalcy (Bonanno 2004; Lilius 2012) in the face of adversity, this conceptual work focuses on possibilities for the cultivation of organizations as spaces to recognize, respond to, and remedy harm or suffering and to play an active role in healing as a "bounce forward" opportunity. This entails harnessing and building on existing strengths as well as developing new strength and capabilities for healing that support more anticipatory and participatory responses to the experience of pain, including harm resulting from external shock, internal scandal, and broader societal injustice.

Second, our work seeks to expand the scope of research that tends to focus on the healing of individuals or suffering within organizations. In contrast to prior work on organizational healing that focuses on healing in response to harm experienced within organizational boundaries (Porath and Pearson 2012; Powley 2013; Powley and Piderit 2008), our paper seeks to expand attention to address organizational opportunity and responsibility for attending to harm experienced outside the boundaries of the organization. The typology we advance invites management scholars and practitioners to re-imagine for whom organizations are responsible. More specifically, we propose that while organizations characterized as emerging and endeavoring spaces of healing may focus on harm experienced by organizational members and stakeholder groups directly within the organization's scope of control, organizations that embody exemplifying spaces of healing actively engage in 
recognizing and remedying harm both within and outside the organization - even when such harm was not caused by the organization. As such, organizations as exemplifying spaces of healing comprehensively demonstrate their commitment to prioritizing the welfare and healing of all their stakeholders broadly defined, including employees, customers, communities, and society (Sisodia and Gelb 2019).

Third, expanding on prior research on organizational healing that illuminates primarily reactive practices to address injury and facilitate recovery (Powley 2013; Powley and Piderit 2008), we conceptualize healing as a proactive and ongoing process rather than a narrowly or temporally bounded set of practices or outcomes in response to events or situations. We propose that crafting organizations as optimal healing spaces calls for organizations to demonstrate an enduring commitment to healing, and that healing is an active, multidimensional process of engagement rather than a set of discrete outcomes. Our conceptualization of organizations as exemplifying spaces of healing sheds light on the elements and practices organizations can leverage and activate in building comprehensive and integrative capacities for recognizing, responding to, and remedying suffering, including systemic harms of societal injustice.

Fourth, our study synthesizes four leading perspectives on healing modalities. Based on our review of the literature we draw on what might be considered best practices and processes of healing from outside the management field (e.g., restorative justice, posttraumatic growth, relational cultural theory, dignity). In weaving insights from these four modalities of healing into our conceptual development of organizations as healing spaces, we extend prior research that frames healing as a reactive or responsive approach to local harm to include more proactive and holistic approaches of healing to broader experiences of suffering. While extant organizational research illuminates a relatively narrow and reactive set of responses to mobilize for healing in organizing contexts (Powley 2013; Powley and Piderit 2008), the typology we advance expands the toolkit of practices and resources available to organizations in cultivating more holistic, proactive, and authentic healing spaces. In particular, the exemplifying healing space highlights the transformational potential of designing and shaping organizations that steward dignity and foster healing by: recognizing and bearing witness to the suffering experienced by others, both within and beyond organizational boundaries; exercising awareness of the role organizations play in generating harm, including the reproduction or reinforcement of systemic injustice; and, acknowledging harm and embracing responsibility for remedying harm, regardless of cause or influence by the organization.

\section{Theoretical Contributions to Social Justice Research}

This work offers several important contributions to the literature on social justice. Our conceptualization of organizations as healing spaces emphasizes the opportunity to view social justice efforts of organizations as spanning organizational boundaries. Organizations characterized as exemplifying spaces of healing seek to heal not only those who are within the organization's boundaries or relatively direct scope of control (i.e., employees, primary stakeholders), but also those individuals or groups who are external or more distal to the organization and have suffered injustices. This highlights that organizations representing exemplifying healing spaces are likely to be concerned with fairness not merely because it serves their instrumental concerns, but also because they perceive a moral imperative to work towards societal healing. This is consistent with Folger and colleagues' deontic model of justice (e.g., Cropanzano, Goldman and Folger 2003; Folger 2001; Folger and 
Glerum 2015) which argues that fair treatment is valued, exercised, and promoted because there is a moral obligation to do so. We advance theorizing that extends the "fairness as deonance" model to suggest that organizations can embrace an ethical responsibility to address injustices well outside their boundaries, including beyond their direct stakeholder communities or conventional scope of activities.

In addition to expanding the scope of healing in organizations our theorizing also extends prior social-psychological work on the "scope of justice" - or the boundary, which defines who is perceived to be deserving of fair and just treatment (e.g., Opotow 1990, 2001; Hafer and Olson 2003). The delineation of those who are perceived as meriting fair treatment and those who are not affects attitudes, beliefs, and behaviors of individuals toward others; those designated as falling outside the boundary are perceived as being less deserving of fair treatment. Scope of justice also has implications for political attitudes. For example, students are more likely to endorse efforts to protect the environment when their scope of justice includes the natural world (Opotow 1994). In our healing spaces typology, organizations characterized as emergent and endeavoring spaces may view only organizational members or primary stakeholders as being deserving of fair treatment and healing. Organizations characterized as exemplifying spaces of healing, however, are likely to conceptualize the scope of justice more expansively and thus seek to heal suffering and injustice that has occurred well beyond their own borders and conventional scope of operations, influence, or responsibility.

Additionally, this work contributes to growing efforts to further integrate two prominent streams of research on social justice. The first has a long history in the management literature and examines when, why, and how justice is enacted and experienced and the consequences of perceived injustice in organizational contexts (e.g., Cropanzano and Ambrose 2015; Greenberg and Colquitt 2005). The second focuses on social justice as a movement and includes recent research on the Black Lives Matter movement (c.f., JonesEversley et al. 2017). While there has been important investigation in this latter stream in management (e.g., Hoang et al. 2021; Iyer and Achia 2020), there is increasing recognition in the field that more must be done (e.g., Akpapuna et al. 2020; Byrd 2018; Mir and Zanoni 2021). In conceptualizing organizations as potential spaces for healing in addressing suffering - including deeply entrenched systemic inequality and oppression, both within and outside the organization - we begin to address this call.

\section{Limitations and Future Research}

Our work to advance a typology of organizations as healing spaces raises a number of important questions and promising possibilities for future research. Our study illuminates three sets of spaces that characterize healing approaches and processes of healing by organizations. Each space represents an opportunity horizon of awareness, commitment, and resources to cultivate and support healing within and by organizations. Yet this typology does not yet map processes or mechanisms for organizations to move from one space to another. Future research might unpack how organizations interested in growing their commitment to healing might develop from emergent to endeavoring to exemplifying spaces. In addition, there may be additional dimensions, nuances, or sub-spaces of healing that would meaningfully advance an understanding of healing in organizational contexts.

Further, we do not assume that organizations automatically demonstrate the same level of commitment to healing when faced with various events or manifestations of suffering or injustice. We suspect that organizations may demonstrate different levels of awareness 
or commitment to healing depending on categories of social injustice (e.g., racism, gender inequality, anti-LGBTQIA+, institutionalized poverty, and other examples of unfair and exploitative treatment of identity groups or discriminatory phenomena). For example, some organizations may demonstrate an emerging space of healing when addressing racial injustice while demonstrating an endeavoring space when addressing gender related injustice. Finally, at the macro-level future conceptualizing might explore if and how this typology can inform healing efforts that acknowledge "all life is one" and address environmental justice that goes beyond centering human life.

The existence of different healing spaces of an organization in response to distinct categories of social injustice may elicit tension, backlash, questions of authenticity, or mistrust by organizational members, stakeholders, and the public. Future research might explore how stakeholders respond to misalignment of healing approaches toward different social categories. For example, if stakeholders perceive that organizations focus on healing that advances gender equality but are tone-deaf to racial issues, what are the implications? Moreover, future research might explore how organizations that are able to cultivate healing spaces for injustices relating to a particular social category can leverage such organizational capability to cultivate amplifying cycles (Feldman and Worline 2012) of greater awareness and commitment for other categories of injustice they have yet to acknowledge. Further, while the typology we develop offers insights about the motivations, roles, and mechanisms at the heart of healing by organizations, it provides limited consideration of explicit hurdles that may impede organizations from actualizing their commitment to healing. Future research might unpack the individual, team, organizational, and institutional influences that challenge organizational commitment to healing and explore ways to overcome such obstacles.

There are interesting potential linkages between the healing modalities we discuss and our typology of the healing organization on the one hand, and Indigenous healing principles and practices on the other that we believe may usefully be explored in future research. Indeed, scholars have drawn parallels between restorative justice and Indigenous healing practices (c.f., Hewitt 2016). Furthermore, Indigenous cultures worldwide have developed extensive traditions to heal themselves from the social injustice of generations of colonialism and the associated historical and intergenerational trauma they have experienced (Duran and Duran 1995; Gone 2007; Kirmayer et al. 2014). While there are widely varying traditional healing practices, many of these practices show clear parallels with the restorative justice, posttraumatic growth, relational cultural, and dignity modalities. For example, among First Nations people in Northern Ontario, sharing circles are an important route to healing, as these groups encourage empathy, shared testimony, and communal connection built on mutual power, and in which Elders and participants are viewed as equal (Marsh 2010; Marsh et al. 2016; Stevenson 1999). Similar connections and potential extensions between our typology and Indigenous healing practices likely exist in many other contexts and can enrich our understanding of the practices that allow organizations to heal within and beyond their boundaries. For example, Indigenous healing practices often build on a holistic integrative perspective of human and the environment (Baskin 2016), which we have yet to map on the western approaches we explore in this paper. Examining Indigenous healing practices may provide an opportunity for scholars to refine and extend our typology and, more generally, to contribute to the important and growing literature on Indigenous theory and practice in the field of management (e.g., Tung and Aycan 2008; Vora and Kainzbauer 2020).

Lastly, cross cultural differences may play an important role in shaping justice norms and conceptions of fairness (Leung and Stephan 2001) and thereby will likely influence 
organizational awareness, motivation, and resources appropriated to pursue healing work. For example, Leung and Stephan (2001) argue that individualistic societies are more likely than collectivistic societies to perceive justice principles as universal and to apply similar justice principles across group boundaries. Similarly, Connor (2003) argues that power distance variation can shape openness to social justice issues, and that low power distance (vs. high power distance) societies are likely to recognize and be open to addressing social injustices. Thus, cross cultural differences shaping the selection of justice principles applied by organizations can introduce important boundary conditions to the typology we propose. Future research could focus on identifying practices that amplify the generative possibilities of healing spaces in certain cultures as well practices that might stifle the cultivation or efficacy of healing spaces in others.

\section{Implications for Practice}

Organizations form the backbone of our society, and institutions from every sector-business, civil society, and government-are increasingly called upon to play a role in healing from economic, social, and ecological disruptions and associated harm. Social justice coverage is now part of the mainstream business press, highlighting issues such as racial justice (Roberts and Grayson 2021), managing social justice within teams (Kruse 2020), and social justice and innovation (Beer 2021). We offer that our compilation of four healing modalities and the associated typology outlining the three healing spaces will be of interest to organizational leaders and managers, especially those involved in human resources, as well as diversity, equity, and inclusion (DEI) and social responsibility programs and initiatives.

In large-scale crises internal and external to an organization, human resource (HR) professionals are called upon to react and help support employees and offer resources that reduce their suffering so that they may address personal challenges and return to work. While standard policies like the Family Medical Leave Act (FMLA) and employee assistance programs (EAPs) focus on well-known long-term stressors affecting work-life balance, our review of healing modalities offers new frameworks for well-being. In particular, we think HR managers and leaders will benefit from a deeper understanding of posttraumatic growth research in cultivating emergent healing spaces dealing with external shocks. This literature underscores the essential role of high-quality connections with others for growth and healing - something that is a natural and daily part of the work environment. Furthermore, insights from the Emergent space of healing can assist HR professionals who aim to support employee healing in three ways. First, training can be expanded to include basic information about organizations as healing spaces. Second, new cultural practices can be developed that support normalizing disclosure about traumas-whether from an environmental crisis (i.e., tornados) or social crisis (i.e., hate crime, sexual violence, etc.). Third, social support can be offered through traditional programs, by encouraging employee affinity groups and the development of a culture of care in organizations.

The \#metoo and Black Lives Matter movements, among others, have called to our collective attention the enormity of changes needed within many institutions to achieve fair, just, and equitable workplaces. These efforts are predicated on the large-scale transformation of policies, practices, and often behaviors. DEI leaders are often the stewards of this essential social justice work within institutions. The dominant strategies for DEI organizational change and development work have usually focused on (1) discrimination-andfairness, (2) access-and-legitimacy in organization, and (3) connecting diversity to work 
perspectives (Thomas and Ely 1996; Ely and Thomas 2020). Our typology parses out and honors the complexity of DEI efforts that often need to operate across the three organizational spaces of healing simultaneously. Healing can be nurtured by organizations in reacting to local concerns from unrest due to racial bias incidents such as police brutality towards people of color (reactive - emerging), responding to hiring bias against women and caregivers (investigative - endeavoring), and systematically appraising how organizational systems, procedures, and policies disadvantage marginalized employees (introspection - exemplifying). Additionally, we suggest that restorative justice, posttraumatic growth, relational culture theory, and the reconciliation model of dignity provide new change strategies that promote healing by engaging with social justice concerns to identify and process inequity violations in more dialogic and non-legalistic models.

Managers responsible for the corporate social responsibility (CSR) efforts of their firms can also benefit from the insights of this research. Since these leaders help support and align an organization's vision, mission, and values and play a key role in engaging with key stakeholders, we suggest that the typology can contribute to expanding and validating CSR efforts from a healing spaces perspective. Initiatives, such as philanthropic humanitarian relief (emergent healing for crisis), recognizing environmental violations and acting to remedy them (endeavoring), and proactively innovating educational resources and engaging in integrative, multi-sectoral programs to support women's empowerment in local and distal communities (exemplifying), can be better designed and more comprehensively implemented with an awareness of and applied guidance from the typology. In a recent reframing of CSR, Zheng (2020) introduces the concept of corporate social justice (CSJ) to include a focus on corporate stewardship of the interests of harmed or disadvantaged societal groups. The typology we advance further extends considerations of CSR by specifically spotlighting opportunities for healing social injustice and transcending more conventional approaches to or measurements of social responsibility by organizations. In instances where there is a fractious history between firms and communities, educating CSR practitioners about the different strategies for dialog and reconciliation, as informed by restorative justice, posttraumatic growth, relational culture theory, and the reconciliation model of dignity, would be greatly beneficial. Furthermore, we anticipate that training in empathy and building high-quality connections will significantly assist the multi-faceted activities required for CSR practitioners to manage internal and external stakeholder relationships. In particular, for CSR practitioners facilitating inter-institutional initiatives across sectors where historic harm could exist (e.g., multi-stakeholder consultations, cross-sector partnerships), we anticipate that competencies in the recognition of a need for reconciliation and the generation of dialog in advance of deeper collaboration would help steward more effective processes and mutually beneficial outcomes.

\section{Conclusion}

We live in a time when historic inequities exacerbated by COVID-19 have reinforced the necessity and urgency for societies and organizations to bring healing into focus. In this paper, we respond to this call and develop a typology that illustrates three ways organizations can function as healing spaces, exploring a range of opportunities for how organizations can better respond to suffering and substantively contribute to remedying harm from systematic bias against marginalized groups via healing. As the opening excerpts remind us, when we realize that all life is one - that all elements of our world are deeply 
interconnected rather than isolated and independent - we can begin to re-imagine the role of organizations as healing spaces in our communities and society. In parallel, as we engage processes of exercising and understanding healing, a deepening awareness of life as unified and integrated can nurture our individual and collective capacities for recognizing and remedying suffering. We view this research on organizations as healing spaces as a promising dawn horizon for awakening organizational scholars and practitioners to the healing potential of organizations as catalysts for societal change. With the plethora of grand challenges and increasing crises and disruptions facing humanity, we hope insights from this work may guide organizations as they are called upon more often to become healing spaces and stewards of social justice.

Acknowledgements We thank David Wasieleski and participants of the Humanistic Management Thought Leadership Conference 2021 for their feedback on early versions of the work we develop in this manuscript. We appreciate insights shared by Paul Harper, which have been invaluable for conceptualizing organizations as healing spaces for social justice. We acknowledge the urgency for healing in our communities and global society for inspiring this research.

\section{Declarations}

Conflict of Interest On behalf of all authors, the corresponding author states that there is no conflict of interest.

\section{References}

Affleck, G., and H. Tennen. 1996. Construing benefits from adversity: Adaptational significance and dispositional underpinnings. Journal of Personality 64 (4): 899-922.

Akpapuna, M., E. Choi, D. Johnson, and J. Lopez. 2020. Encouraging multiculturalism and diversity within organizational behavior management. Journal of Organizational Behavior Management 40 (3-4): 186-209.

Anand, V., B. Ashforth, and M. Joshi. 2004. Business as usual: The acceptance and perpetuation of corruption in organization. Academy of Management Perspectives 18 (2): 39-53.

Armour, M.P., and M.S. Umbreit. 2006. Victim forgiveness in restorative justice dialogue. Victims \& Offenders 1: 123-140.

Ashcraft, K. 2013. The glass slipper: "Incorporating" occupational identity in management studies. Academy of Management Review 38 (1): 6-31. https://doi.org/10.5465/amr.2010.0219.

Barry, B. 2005. Why social justice matters. Cambridge: Polity Press.

Baskin, C. 2016. Spirituality: The core of healing and social justice from an indigenous perspective. Spirituality in the Workplace: A Philosophical and Social Justice Perspective 16: 51-60.

Batson, C.D., S.C. Sympson, J.L. Hindman, P. Decruz, R.M. Todd, J.L. Weeks, G. Jennings, and C.T. Burns. 1996. "I've been there, too": Effect on empathy of prior experience with a need. Personality and Social Psychology Bulletin 22 (5): 474-482.

Beer, J. 2021. How Ben \& Jerry's has swirled social justice into its innovative business. Fast Company, May 9, 2021. https://www.fastcompany.com/90600409/ben-jerrys-most-innovative-companies-2021?partn er=rss\&utm_source=rss\&utm_medium $=$ feed\&utm_campaign $=r s s+$ fastcompany\&utm_content=rss? cid $=$ search

Black, L.W. 2008. Deliberation, storytelling, and dialogic moments. Communication Theory 18: 93-116.

Block, P. 2009. Community: The structure of belonging. San Francisco: Berrett-Koehler.

Bonanno, G.A. 2004. Loss, trauma, and human resilience: Have we underestimated the human capacity to thrive after extremely aversive events? American Psychologist 59: 20-28.

Bornstein, D. 2007. How to change the world: Social entrepreneurs and the power of new ideas. $2 \mathrm{nd}$ ed. New York: Oxford University Press.

Borton, I.M., and G.D. Paul. 2015. Problematizing the healing metaphor of restorative justice. Contemporary Justice Review 18: 257-273. 
Braithwaite, J. 1999. Restorative justice: Assessing optimistic and pessimistic accounts. Crime and Justice 25: 1-127.

Braithwaite, J. 2002. Setting standards for restorative justice. British Journal of Criminology 42: 563-577.

Brush, C.G. 1999. Women entrepreneurs: Moving beyond the glass ceiling. Academy of Management Review 24 (3): 586-589. https://doi.org/10.5465/AMR.1999.2202143.

Byrd, M.Y. 2018. Does HRD have a moral duty to respond to matters of social injustice? Human Resource Development International 21 (1): 3-11.

Calhoun, L. G., \& Tedeschi, R. G. 2006. The Foundations of Posttraumatic Growth: An Expanded Framework. In L. G. Calhoun \& R. G. Tedeschi (Eds.), Handbook of posttraumatic growth: Research \& practice (pp. 3-23). Lawrence Erlbaum Associates Publishers.

Cartabuke, M., J.W. Westerman, J.Z. Bergman, B.G. Whitaker, J. Westerman, and R.I. Beekun. 2019. Empathy as an antecedent of social justice attitudes and perceptions. Journal of Business Ethics 157 (3): 605-615.

Clark, C. M. 2012. "Healing from the Bitter Pill of Incivility". Minority Nurse 32-34.

Colquitt, J.A., J. Greenberg, and C.P. Zapata-Phelan. 2005. What is organizational justice? A historical overview. In Handbook of organizational justice, ed. J. Greenberg and J.A. Colquitt, 3-56. Mahwah: Lawrence Erlbaum Associates Publishers.

Connor, D.S. 2003. Socially appraising justice: A cross-cultural perspective. Social Justice Research 16 (1): 29-39.

Cropanzano, R., and M.L. Ambrose, eds. 2015. The Oxford handbook of justice in the workplace. New York: Oxford University Press https://doi.org/10.1093/oxfordhb/9780199981410.001.0001.

Cropanzano, R., and D.E. Rupp. 2008. Social exchange theory and organizational justice: Job performance, citizenship behaviors, multiple foci, and a historical integration of two literatures. In Research in social issues in management: Justice, morality, and social responsibility, ed. S. Gilliland, D. Steiner, and D. Skarlicki, 63-99. Greenwich: Information Age Publishing.

Cropanzano, R., B. Goldman, and R. Folger. 2003. Deontic justice: The role of moral principles in workplace fairness. Journal of Organizational Behavior 24: 1019-1024. https://doi.org/10.1002/job. 228.

Dare, J. 2016. Will the truth set us free? An exploration of CSR motive and commitment. Business and Society Review 121 (1): 85-122.

De Maria, W. 2010. After the scandal - Recovery options for damaged organizations. Journal of Management \& Organization 16 (1). https://doi.org/10.5172/jmo.16.1.66.

Drucker, P. 1999. Management challenges for the $21^{\text {st }}$ century. New York: HarperCollins.

DuBose, J., L. MacAllister, and K.H. March. 2018. Exploring the concept of healing spaces. Health Environments Research \& Design Journal 11 (1): 43-56.

Duran, E., and B. Duran. 1995. Native American postcolonial psychology. Albany: SUNY Press.

Dutton, J.E., and E.D. Heaphy. 2003. The power of high-quality connections. In Positive organizational scholarship: Foundations of a new discipline, ed. K.S. Cameron, J.E. Dutton, and R.E. Quinn, 263-278. San Francisco: Berrett-Koehler.

Dutton J. E., Worline, M. C., Frost P. J, \&. Lilius J. 2006. Explaining compassion organizing. Administrative Science Quarterly; 51(1): 59-96. https://doi.org/10.2189/asqu.51.1.59.

Edmondson, A. 2018. The fearless organization: Creating psychological safety in the workplace for learning, innovation, and growth. Hoboken, NJ: John Wiley \& Sons.

Ely, R., and D.A. Thomas 2020. Getting serious about diversity: Enough already with the business case. Harvard Business Review, 98, no. 6 (November-December 2020).

Fazio, R.J., and L.M. Fazio. 2005. Growth through loss: Promoting healing and growth in the face of trauma, crisis, and loss. Journal of Loss and Trauma 10 (3): 221-252.

Fehr, R., and M.J. Gelfand. 2012. The forgiving organization: A multilevel model of forgiveness at work. Academy of Management Review 37: 664-688.

Feldman, M.S., and M.C. Worline. 2012. Resources, resourcing and ampliative cycles in organizations. In The oxford handbook of positive organizational scholarship: 629-641, ed. G.M. Spreitzer and K.S. Cameron. New York: Oxford University Press.

Firth, K., K. Smith, B.R. Sakallaris, D.M. Bellanti, C. Crawford, and K.C. Avant. 2015. Healing, a concept analysis. Global Advances in Health and Medicine 4: 44-50. https://doi.org/10.7453/Gahmj. 2015.056 .

Fletcher, J.K. 1999. Disappearing acts: Gender, power and relational practice at work. Cambridge: MIT Press.

Fletcher, J.K., and B.R. Ragins. 2007. Stone center relational cultural theory: A window on relational mentoring. In The handbook of mentoring at work: Theory, research, and practice, ed. B.R. Ragins and K.E. Kram, 373-399. Los Angeles: Sage. 
Folger, R. 2001. Fairness as deonance. In Theoretical and cultural perspectives on organizational justice, ed. S. Gilliland, D. Steiner, and D. Skarlicki, 3-33. Greenwich: Information Age Publishing.

Folger, R., and D.R. Glerum. 2015. Justice and deonance: "You ought". In Oxford handbook of justice in the workplace, ed. R. Cropanzano and M.L. Ambrose, 331-350. New York: Oxford University Press.

Frey, L.M., and A. Fulginiti. 2017. Talking about suicide may not be enough: Family reaction as a mediator between disclosure and interpersonal needs. Journal of Mental Health 26 (4): 366-372.

Frey, L.M., A. Fulginiti, L. Sheehan, N. Oexle, D.L. Stage, and J. Stohlmann-Rainey. 2020. What's in a word? Clarifying terminology on suicide-related communication. Death Studies 44 (12): 808-818. https://doi.org/10.1080/07481187.2019.1614111.

Gentleman, A. 2007. Gap moves to recover from child labor scandal. New York Times, November 15, 2007. Accessed 10 June 2021: https://www.nytimes.com/2007/11/15/business/worldbusiness/ 15iht-gap.1.8349422.html.

Gone, J.P. 2007. "We never was happy living like a Whiteman": Mental health disparities and the postcolonial predicament in American Indian communities. American Journal of Community Psychology 40 (3-4): 290-300.

Goodstein, J., and K. Aquino. 2010. And restorative justice for all: Redemption, forgiveness, and reintegration in organizations. Journal of Organizational Behavior 31: 624-628.

Greenbaum, R., J. Bonner, T. Gray, and M. Mawritz. 2020. Moral emotions: A review and research agenda for management scholarship. Journal of Organizational Behavior 41 (2): 95-114.

Greenberg, J., and J.A. Colquitt, eds. 2005. Handbook of organizational justice. Mahwah: Lawrence Erlbaum Associates Publishers.

Hafer, C.L., and J.M. Olson. 2003. An analysis of empirical research on the scope of justice. Personality and Social Psychology Review 7 (4): 311-323.

Hammack, P.L., ed. 2018. The oxford handbook of social psychology and social justice. New York: Oxford University Press.

Harbold, W. 1969. Justice in the thought of Pierre-Joseph Proudhon. The Western Political Quarterly 22 (4): 723-741. https://doi.org/10.2307/447031.

Hewitt, J.G. 2016. Indigenous restorative justice: Approaches, meaning \& possibility. University of New Brunswick Law Journal 67: 313-335.

Hicks, D. 2011. Dignity: The essential role it plays in resolving conflict. New Haven: Yale University Press.

Hicks, D. 2016 Dignity: Its Essential Role in Resolving Conflict. New Heaven: Yale University Press.

Hicks D. 2018. Leading with Dignity: How to create a culture that brings out the best in people. New Heaven: Yale University Press.

Hoang, T.M.H., H.A. Neville, V.P. Poteat, and L.B. Spanierman. 2021. Examination of social justice behaviors: Testing an integrated model. Journal for Social Action in Counseling \& Psychology 12 (2): 34-53. https://doi.org/10.33043/JSACP.12.2.34-53.

International Labour Organization 2008. ILO declaration on social justice for a fair globalization. Adopted by the International Labour Conference at its Ninety-seventh session, Geneva, 10 June 2008. Accessed May 8, 2021. https://www.ilo.org/wcmsp5/groups/public/\%2D\%2D-dgreports/\% 2D\%2D-cabinet/documents/genericdocument/wcms_371208.pdf.

Iyer, A., and T. Achia 2020. Mobilized or marginalized? Understanding low-status groups' responses to social justice efforts led by high-status groups. Journal of Personality and Social Psychology. Advance online publication. https://doi.org/10.1037/pspi0000325.

Janoff-Bulman, R. 1992. Shattered assumptions: Towards a new psychology of trauma. New York: Free Press.

Janoff-Bulman, R. 2006. Schema-change perspectives on posttraumatic growth. In Handbook of posttraumatic growth: Research and practice, ed. L.G. Calhoun and R.G. Tedeschi, 81-99. Mahwah: Psychology Press.

Jones-Eversley, S., A.C. Adedoyin, M.A. Robinson, and S.E. Moore. 2017. Protesting black inequality: A commentary on the civil rights movement and Black lives matter. Journal of Community Practice 25 (3-4): 309-324. https://doi.org/10.1080/10705422.2017.1367343.

Jordan, J.V., ed. 1997. Women's growth in diversity: More writings from the stone center. New York: Guilford Press.

Jordan, J.V., A.G. Kaplan, J.B. Miller, I.P. Stiver, and J.L. Surrey. 1991. Women's growth in connection: Writings from the stone center. New York: Guilford Press.

Joseph S, Linley PA. 2005 Positive Adjustment to Threatening Events: An Organismic Valuing Theory of Growth through Adversity. Review of General Psychology. 9(3):262-280. https://doi.org/10. 1037/1089-2680.9.3.262. 
"Justice" and "just". 2021. Merriam-Webster.com. https://www.merriam-webster.com (23 March 2021).

Kabadayi, S., Alkire, (née Nasr) L., Broad, G.M., Livne-Tarandach, R. Wasieleski, D., and A.M. Puente 2019. Humanistic Management of Social Innovation in service (SIS): An interdisciplinary framework. Humanistic Management Journal, 4: 159-185. https://doi.org/10.1007/s41463-019-00063-9.

Kalfas, I. H. 2001. Principles of bone healing. Neurosurgical Focus 10(4), 1-4.

Kechen, M. 2013. Social justice: Concepts, principles, tools and challenges. A publication of the United Nations economic and social Commission for West Asia; United Nations economic and social council. E/ESCWA/SDD/2013/Technical Paper.9; December 16, 2013.

Kirmayer, L.J., J.P. Gone, and J. Moses. 2014. Rethinking historical trauma. Transcultural Psychiatry 51 (3): 299-319. https://doi.org/10.1177/1363461514536358.

Kruse, K. 2020, July 7. 3 ways managers can address social justice issues with their teams. Forbes. https:// www.forbes.com/sites/kevinkruse/2020/07/07/3-ways-managers-can-address-social-justice-issueswith-their-teams $/$ sh $=2 \mathrm{e} 07986335 \mathrm{cc}$.

Laasch, O., Dierksmeier, C. Livne-Tarandach, R. Pirson, M., Fu, P., and Q. Qu 2019. Humanistic management performativity "in the wild': The role of performative bundles of practices. Presented at the Academy of Management Conference, Boston, USA.

Leung, K., and W.G. Stephan. 2001. Social justice from a cultural perspective. In The handbook of culture and psychology, ed. D. Matsumoto, 375-410. London: Oxford University Press.

Lilius, J.M. 2012. Recovery at work: Understanding the restorative side of "depleting" client interactions. Academy of Management Review 37: 569-588.

Linley, P.A., and S. Joseph. 2004. Positive change following trauma and adversity: A review. Journal of Traumatic Stress 17 (1): 11-21.

Luthar, S.S., D. Cicchetti, and B. Becker. 2000. The construct of resilience: A critical evaluation and guidelines for future work. Child Development 71: 543-562.

Maak, T. 2008. Undivided corporate responsibility: Towards a theory of corporate integrity. Journal of Business Ethics 82 (2): 353-368.

Maitlis, S. 2011. Posttraumatic growth: A missed opportunity for positive organizational scholarship. In The oxford handbook of positive organizational scholarship, ed. K.S. Cameron and G.M. Spreitzer, 909-923. London: Oxford University Press.

Maitlis, S. (2012). Posttraumatic growth. In K. S. Cameron \& G. M. Spreitzer (Eds.), The Oxford handbook of positive organizational scholarship (pp. 909-923). Oxford University Press.

Manyika, J., and M. Tuin 2020. It's time to build $21^{\text {st }}$ century companies: Learning to thrive in a radically different world. Milken Institute Review. Published May 4, 2020. Accessed 8 May 2021. https://www. milkenreview.org/articles/its-time-to-build-21st-century-companies.

Marquis, C. 2020. Better business: How the B corp movement is remaking capitalism. New Haven: Yale University Press.

Marsh, T.N. 2010. Enlightenment is letting go! Healing from trauma, addiction, and multiple loss. Bloomington: Authorhouse.

Marsh, T.N., S. Cote-Meek, N.L. Young, L.M. Najavits, and P. Toulouse. 2016. Indigenous healing and seeking safety: A blended implementation project for intergenerational trauma and substance use disorders. The International Indigenous Policy Journal 7 (2): 1-37. https://doi.org/10.18584/iipj.2016.7. 2.3 .

Matten, D., and J. Moon. 2008. "Implicit" and "explicit" CSR: A conceptual framework for a comparative understanding of corporate social responsibility. Academy of Management Review 33: 404-424.

Merriam Webster 2021, justice, Merriam Webster, Inc. https://www.merriam-webster.com/dictionary/justi ce

Miller, D. 2017 "Justice", The Stanford encyclopedia of philosophy (Fall 2017 Edition), Edward N. Zalta (ed.). https://plato.stanford.edu/archives/fall2017/entries/justice/.

Miller, J.B. 1976. Toward a new psychology of women. Boston: Beacon Press.

Miller, J.B., and I. Stiver. 1997. The healing connection: How women form relationships in therapy and in life. Boston: Beacon Press.

Mills, C., and J. Ballantyne. 2016. Social justice and teacher education: A systematic review of empirical work in the field. Journal of Teacher Education 67 (4): 263-276. https://doi.org/10.1177/0022487116 660152.

Mir, R., and P. Zanoni. 2021. Black lives matter: Organization recommits to racial justice. Organization 28 (1): $3-7$

Mitchell, J.K., ed. 1996. The long road to recovery: Community responses to industrial disaster. Tokyo: United Nations University Press.

Mooney, C.G. 2009. Theories of attachment: An introduction to Bowlby, Ainsworth, Gerber, Brazelton, Kennell, and Klaus. St. Paul: Redleaf Press. 
Morris, A. 2002. Critiquing the critics: A brief response to critics of restorative justice. British Journal of Criminology 42: 596-615.

Murnion, W.E. 1989. The ideology of social justice in economic justice for all. Journal of Business Ethics 8 (11): 847-854.

Nkomo, S.M., M.P. Bell, L.M. Roberts, A. Joshi, and S.M.B. Thatcher. 2019. Diversity at a critical juncture: New theories for a complex phenomenon. Academy of Management Review 44 (3): 498-517. https:// doi.org/10.5465/amr.2019.0103.

Nolen-Hoeksema, S., and C. Davis. 2004. Theoretical and methodological issues in the assessment and interpretation of posttraumatic growth. Psychological Inquiry 15 (1): 60-64.

Opotow, S. 1990. Moral exclusion and injustice: An introduction. Journal of Social Issues 46 (1): 1-20.

Opotow, S. 1994. Predicting protection: Scope of justice and the natural world. Journal of Social Issues 50 (3): 49-63.

Opotow, S. 2001. Reconciliation in times of impunity: Challenges for social justice. Social Justice Research 14: $149-170$.

Ornstein, A.C. 2017. Social justice: History, purpose and meaning. Social Science and Public Policy 54: 541-548. https://doi.org/10.1007/s12115-017-0188-8.

Park, C.L. 2010. Making sense of the meaning literature: An integrative review of meaning making and its effects on adjustment to stressful life events. Psychological Bulletin 136 (2): 257-301.

Pirson, M., and R. Livne-Tarandach. 2020. Restoring dignity with open hiring- Greyston bakery and the recognition of value. Rutgers Business Review 5 (2): 236-247.

Porath, C.L., and C.M. Pearson. 2012. Emotional and behavioral responses to workplace incivility and the impact of hierarchical status. Journal of Applied Social Psychology 42 (S1): E326-E357.

Porter, M.E., and M.R. Kramer. 2006. Strategy and society: The link between competitive advantage and corporate social responsibility. Harvard Business Review 84 (12): 78-92.

Powley, E.H. 2012. Organizational healing: A relational process to handle major disruption. In The Oxford handbook of positive organizational scholarship, ed. K.S. Cameron and G.M. Spreitzer, 855-866. London: Oxford University Press.

Powley, E.H. 2013. The process and mechanisms of organizational healing. The Journal of Applied Behavioral Science. 49 (1): 42-68.

Powley, E.H., and S.K. Piderit. 2008. Tending wounds: Elements of the organizational healing process. Journal of Applied Behavioral Science 44: 134-149.

Roberts, L., and M. Grayson 2021. Businesses must be accountable for their promises on racial justice. Harvard Business Review. https://hbr-org.cdn.ampproject.org/c/s/hbr.org/amp/2021/06/businesses-mustbe-accountable-for-their-promises-on-racial-justice.

Romero, M. 2020. Sociology engaged in social justice. American Sociological Review 85 (1): 1-30. https:// doi.org/10.1177/0003122419893677.

Sakallaris, B.R., L. MacAllister, M. Voss, K. Smith, and W.B. Jonas. 2015. Optimal healing environments. Global Advances in Health and Medicine 4: 40-45. https://doi.org/10.7453/gahmj.2015.043.

Samar, V.J. 1999. Positive rights and the problem of social justice. Business Ethics Quarterly 9 (2): 361-375.

Schilling, J.A. 1968. Wound healing. Physiological Reviews 48: 374-423.

Sherman, L.W., H. Strang, G. Barnes, D.J. Woods, S. Bennett, N. Inkpen, D. Newbury-Birch, M. Rossner, C. Angel, M. Mearns, and M. Slothower. 2015. Twelve experiments in restorative justice: The Jerry Lee program of randomized trials of restorative justice conferences. Journal of Experimental Criminology 11 (4): 501-540.

Shrivastava, P. 1995. The role of corporations in achieving ecological sustainability. Academy of Management Review 20 (4): 936-960. https://doi.org/10.5465/AMR.1995.9512280026.

Sisodia, R., and M.J. Gelb. 2019. The healing organization: Awakening the conscience of business to help save the world. Nashville: HarperCollins.

Steckler, E. 2012. Toward a theory of organizational authenticity from a stakeholder perspective. Academy of Management Proceedings 2012 (1): 16807. https://doi.org/10.5465/AMBPP.2012.16807abstract.

Steckler, E. 2014. The social construction of organizational authenticity by stakeholders. Unpublished doctoral dissertation, Boston College, Chestnut Hill.

Stevenson, J. 1999. The circle of healing. Native Social Work Journal 2: 8-21.

Surrey, J. 1985 "The self in relation (Working Paper No. 13)." Wellesley, MA: Wellesley Centers for Women, Wellesley College.

Tedeschi, R., and L. Calhoun. 1995. Trauma \& transformation: Growing in the aftermath of suffering. Thousand Oaks: SAGE.

Tedeschi, R.G., and L.G. Calhoun. 2004. Posttraumatic growth: Conceptual foundations and empirical evidence. Psychological Inquiry 15: 1-18. 
Thomas, D.A., and R.D. Ely 1996. Making differences matter: A new paradigm for managing diversity. Harvard Business Review, Sept.-Oct.: 79-90.

Torrie, M. (n.d.) The Intention. http://web.cs.ucla.edu/ klinger/intention.html .

Tung, R.L., and Z. Aycan. 2008. Key success factors and indigenous management practices in SMEs in emerging economies. Journal of World Business 43 (4): 381-384. https://doi.org/10.1016/j.jwb.2008. 04.001 .

Tyler, T.R. 2006. Restorative justice and procedural justice: Dealing with rule breaking. Journal of Social Issues 62 (2): 307-326.

Tyler, T.R., R. Boeckmann, H.J. Smith, and Y.J. Hou. 1997. Social justice in a diverse society. Boulder: Westview Press.

Umbreit, M.S., R.B. Coates, and B. Vos. 2007. Restorative justice dialogue: A multi-dimensional, evidencebased practice theory. Contemporary Justice Review 10: 23-41.

United Nations. 2006. Social justice in an open world: The role of the United Nations. https://www.un.org/ esa/socdev/documents/ifsd/SocialJustice.pdf United Nations: New York.

Vora, D., and A. Kainzbauer. 2020. Humanistic leadership in Thailand: A mix of indigenous and global aspects using a cross-cultural perspective. Cross Cultural \& Strategic Management 27 (4): 665-687. https://doi.org/10.1108/CCSM-01-2020-0008.

Wenzel, M., T.G. Okimoto, N.T. Feather, and M. Platow. 2008. Retributive and restorative justice. Law and Human Behavior 32: 375-389.

Worline, M.C., and J.E. Dutton. 2017. Awakening compassion at work: The quiet power that elevates people and organizations. Oakland: Sounds True.

Zehr, H. 1990. Changing lenses: A new focus for crime and justice. Scottdale: Herald Press.

Zehr, H. 2002. The little book of restorative justice. Intercourse: Good Books.

Zehr, H. 2009. The intersection of restorative justice with trauma healing, conflict transformation, and peacebuilding. Journal of Peace \& Justice Studies 18 (1/2): 20-30.

Zheng, L. 2020. We're entering the age of corporate social justice. Harvard Business Review (Digital Article). June $15,2020$.

Publisher's Note Springer Nature remains neutral with regard to jurisdictional claims in published maps and institutional affiliations.

\section{Authors and Affiliations}

\section{Reut Livne-Tarandach ${ }^{1}$ (D) . Erica Steckler ${ }^{2}$ D . Jennifer Leigh ${ }^{3}$ (D) . Sara Wheeler-Smith ${ }^{1}$}

Erica Steckler

Erica_Steckler@uml.edu

Jennifer Leigh

jleigh4@naz.edu

Sara Wheeler-Smith

sara.wheeler-smith@manhattan.edu

1 O’Malley School of Business, Manhattan College, 4513 Manhattan College Parkway, Riverdale, NY 10471, USA

2 Manning School of Business, University of Massachusetts Lowell, University Crossing, Suite 420, 220 Pawtucket St., Lowell, MA 01854-2874, USA

3 School of Business and Leadership, Nazareth College, 4245 East Ave, Rochester, NY 14618, USA 